\title{
Characterization of Fonsecaea pedrosoi melanin
}

\author{
Celuta S. Alviano, ${ }^{1 *}$ Sonia R. Farbiarz, ${ }^{2}$ Wanderley De Souza, $^{2}$ Jayme Angluster $^{1}$ and \\ LuIz R. TRavassos ${ }^{3}$ \\ ${ }^{1}$ Instituto de Microbiologia and ${ }^{2}$ Instituto de Biofisica Carlos Chagas Filho, Universidade Federal do Rio de Janeiro, Ilha \\ do Fundão, 21941, Rio de Janeiro, Brazil \\ ${ }^{3}$ Disciplina de Micologia, Escola Paulista de Medicina, São Paulo, SP 04023, Brazil
}

(Received 27 June 1990; revised 21 November 1990; accepted 28 November 1990)

\begin{abstract}
The constituents of the melanin complex from mycelial forms of Fonsecaea pedrosoi were partially characterized. The pigment was mainly accumulated on large alkali-extractable, electron-dense cytoplasmic bodies (melanosomes) and, apparently, on the outer layer of the cell wall as external deposits within verrucose outgrowths. Using electron microscopy and Thiéry's periodate/thiosemicarbazide/silver proteinate staining method, glycogenlike particles were also detected at the periphery of the cells. Melanin constituents comprised aromatic and aliphatic/glycosidic structures with a predominance of the latter. Infrared spectra showed the presence of hydroxyl, carbonyl and carboxyl groups. The aliphatic/glycosidic moiety consisted of fatty acids and polysaccharides with protein, in a ratio protein/polysaccharide 1:15. Rhamnose, mannose, galactose and glucose (in the ratio $1: 2: 4: 3.5$ ) were the constituents of the polysaccharide. Lipid components included even-numbered, saturated and unsaturated fatty acids (in the ratio 2:1) ranging from $\mathrm{C}_{16}$ to $\mathrm{C}_{18}$. Palmitic and oleic acids were the prominent fatty acids. Aspartic and glutamic acids, leucine, glycine and alanine were the major amino acids. Nonpigmented cells of $\boldsymbol{F}$. pedrosoi were studied for comparison with the pigmented forms: they did not accumulate acidinsoluble precursors of melanin.
\end{abstract}

\section{Introduction}

Fonsecaea pedrosoi is one of the agents of chromoblastomycosis, a chronic infection characterized by dry, crusted, warty, violaceous lesions that spread locally but are usually limited to the skin and subcutaneous tissue. Tissue forms of the fungus comprise hyphal segments and brown, thick-walled sclerotic bodies. Cultured forms grown in a synthetic medium for prolonged periods at $28^{\circ} \mathrm{C}$ are mainly filamentous (Butterfield \& Yong, 1976).

Dematiaceous fungi pathogenic to humans usually form dark polymeric pigments, generally referred to as melanins, which are deposited on the fungal cell wall (Ellis \& Griffiths, 1974; Ellis, 1976). It has been suggested that in these pathogens the pentaketide biosynthetic pathway is the predominant mechanism for cell wall melanization (Taylor et al., 1987). In many cases, however, pigment biosynthesis may involve the

Abbreviations: CD, Czapeck-Dox (medium); SDA, Sabouraud dextrose agar; TFA, trifluoroacetic acid. phenol oxidase enzyme system. The physiological roles of fungal melanins are still under investigation (Cole, 1986). Melanins may influence the storage of water and ions (White, 1958), and render micro-organisms resistant to lysis (Bull, 1970) and solar radiation (Sussman, 1968). Inhibition of the pentaketide pathway of melanin synthesis in Wangiella dermatitidis may decrease the pathogenicity of this fungus (Geis et al., 1984).

There have been few studies on the surface structures of dark-pigmented $F$. pedrosoi, but we have reported the presence of sialylated constituents on the external layers of the cell wall in both the hyphae and the conidia of this fungus (Souza et al., 1986).

Both sialyl residues and melanin may play an important role in the pathogenicity of this fungus and of other dark-pigmented fungi which cause disease in plants and animals (Cole, 1986; Travassos, 1985).

The purpose of this investigation was to study the localization and chemical structure of the melanin complex from mycelial forms of $F$. pedrosoi grown in a synthetic medium. 


\section{Methods}

Organism. A pathogenic strain of $F$. pedrosoi was isolated from a human patient with chromoblastomycosis (Oliveira et al., 1973). The fungus was maintained in Sabouraud dextrose agar (SDA), covered with a layer of mineral oil $(0.5 \mathrm{ml})$, at $4{ }^{\circ} \mathrm{C}$. Transfers were made at six month intervals.

Culture media and fungal morphology. The mycelium grown on SDA was used to inoculate $200 \mathrm{ml}$ Czapeck-Dox (CD) medium containing $\left(\mathrm{g} \mathrm{I}^{-1}\right)$ : sucrose, $30 ; \mathrm{NaNO}_{3}, 2 ; \mathrm{K}_{2} \mathrm{HPO}_{4}, 1 ; \mathrm{MgSO}_{4} .7 \mathrm{H}_{2} \mathrm{O}, 0 \cdot 5, \mathrm{KCl}$, $0.5 ; \mathrm{FeSO}_{4} .7 \mathrm{H}_{2} \mathrm{O}, 0.01 ; \mathrm{pH} 5-6$. Cultures $(100 \mathrm{ml})$ were grown at $37^{\circ} \mathrm{C}$ for $14 \mathrm{~d}$, without shaking. These were then used as inocula for 3-litre cultures. The fungal morphology under these conditions consisted of hyphae with no conidia. For conidia formation, cultures were incubated, at $37^{\circ} \mathrm{C}$ with shaking for $4 \mathrm{~d}$. Shaken cultures contained both hyphae and conidia, and were dark-pigmented. Non-pigmented cultures were grown in flasks filled almost to the top, to decrease aeration, with $C D$ medium, and were incubated in the dark. In both cases shaking ensured formation of conidia. Pigmented and nonpigmented fungal cultures are shown in Fig. 1.

To obtain sclerotic forms, or forms very similar to those found in infected tissues, a new, chemically defined medium was used with the following composition per litre: glycerol, $5 \mathrm{ml} ; \mathrm{MgSO}_{4} \cdot 7 \mathrm{H}_{2} \mathrm{O}, 0 \cdot 1 \mathrm{~g}$; $\mathrm{KH}_{2} \mathrm{PO}_{4}, 1.8 \mathrm{~g} ; \mathrm{NH}_{4} \mathrm{NO}_{3}, 1.5 \mathrm{~g}$; biotin, $5 \mu \mathrm{g}$; thiamin. $\mathrm{HCl}, 100 \mu \mathrm{g}$; $\mathrm{pH} 4 \cdot 5-5 \cdot 0$. Incubation was at $37^{\circ} \mathrm{C}$ for $14 \mathrm{~d}$ with shaking.

Isolation and purification of the melanin-like pigment. The black pigment of $F$. pedroso $i$ was restricted to the cells and did not diffuse into the medium. The pigment produced in the mycelium was extracted with $0.5 \mathrm{M}-\mathrm{NaOH}$ at room temperature in a Waring blender for $10 \mathrm{~min}$, followed by shaking overnight in the same alkali solution. The cell extract was filtered and centrifuged at $10000 \mathrm{~g}$. The supernatant was acidified to $\mathrm{pH} 1.5$ with $1 \mathrm{M}-\mathrm{HCl}$, and the precipitate containing the pigment was recovered by centrifugation at $5000 \mathrm{~g}$, then repeatedly washed with distilled water. The insoluble pigment was resuspended in $0 \cdot 1 \mathrm{M}-\mathrm{HCl}$ and centrifuged at $10000 \mathrm{~g}$ to remove cell debris. The precipitate was washed several times with $0 \cdot 1 \mathrm{M}-\mathrm{HCl}$ until the washes were colourless. Finally it was dialysed against distilled water, lyophilized and stored under nitrogen.

Analytical methods. Pigmented materials were chemically analysed using extracts from non-pigmented cells of similar morphology, obtained by the same procedure, as controls.

Mineral contents (ash) were determined by heating the insoluble pigment at $700{ }^{\circ} \mathrm{C}$ for $4 \mathrm{~h}$.

Total nitrogen was determined by the micro-Kjeldahl method (Bremner, 1965), and total carbon by dry combustion at $900^{\circ} \mathrm{C}$ in the presence of a metal catalyst (Coleman cuprox platinum catalyst) with a stream of high-purity oxygen, using a modified Coleman nitrogen analyser. The $\mathrm{CO}_{2}$ produced was absorbed in $0.2 \mathrm{M}-\mathrm{KOH}$ solutions and the amount absorbed was determined by titration.

Phosphate content was determined by the method of Ames (1966).

Each value reported is the mean of at least two determinations and corresponds to dry, ash-free materials.

Carbohydrate components. Total carbohydrate was determined by the method of Dubois et al. (1956) using mannose as standard.

Polymers were hydrolysed with $0.3 \mathrm{M}$-trifluoroacetic acid (TFA) (Morrison, 1988). Monosaccharide components were determined as alditol acetate derivatives (Sawardeker et al., 1965) by GLC with stainless-steel columns, $6 \mathrm{ft} \times \frac{1}{8}$ in $(1.82 \mathrm{~m} \times 3 \mathrm{~mm})$, packed with $2 \%$ neopentylglycolsuccinate on 100-120 mesh Gas Chrom Q at $200^{\circ} \mathrm{C}$. An internal standard of arabitol acetate was used.

Monosaccharides were also identified by descending paper chromatography on Whatman no. 1 paper, using $n$-butanol/ethanol/water

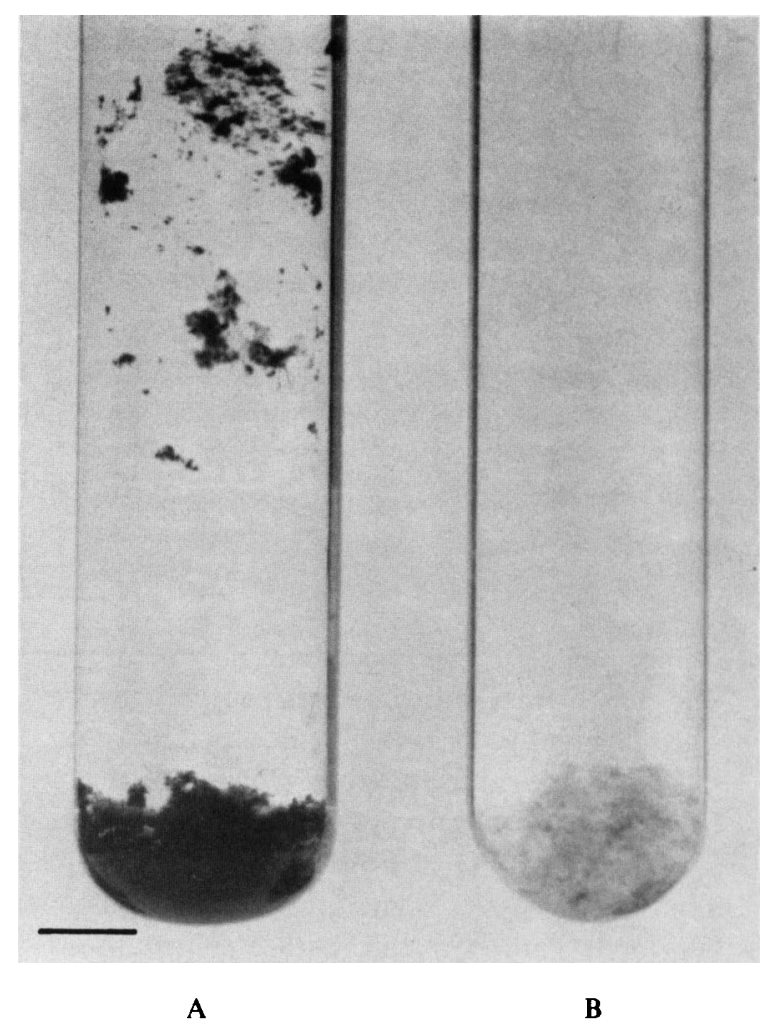

Fig. 1. Cultures of $F$. pedrosoi in $\mathrm{CD}$ medium. (A) Pigmented mycelium and conidia from shaken culture at $37^{\circ} \mathrm{C}$; (B) nonpigmented mycelium culture with low aeration. $B a r, 1 \mathrm{~cm}$.

( $3: 2: 2$, by vol.) as solvent and ammoniacal $\mathrm{AgNO}_{3}$ as the spotrevealing reagent.

Partial hydrolysis was carried out in $0.01 \mathrm{M}$-TFA at $100^{\circ} \mathrm{C}$ for $3.5 \mathrm{~h}$. The hydrolysate was filtered and washed three times with distilled water by evaporation in vacuo. Filtrates were pooled and aliquots were analysed by paper chromatography and GLC, as described above.

To determine the contents of amino sugars, polymers were hydrolysed for $18 \mathrm{~h}$ at $100^{\circ} \mathrm{C}$ with $6 \mathrm{M}-\mathrm{HCl}$. The hydrolysate was analysed by descending paper chromatography on Whatman no. 1 paper, using ethylacetate/pyridine/water $(8: 2: 1$, by vol.) as solvent and saturated $\mathrm{AgNO}_{3}$ in acetone as the spot-revealing reagent.

Hexosamines were also determined colorimetrically, by the method of Belcher et al. (1954).

Sialic acids were extracted and analysed as described by Souza et al. (1986).

Hexuronic acids were analysed by the method of Galambos (1967).

Amino acid analysis. Amino acids from the fungal pigment were released by hydrolysis with $6 \mathrm{M}-\mathrm{HCl}$ for $22 \mathrm{~h}$, in sealed tubes, at $110^{\circ} \mathrm{C}$. After hydrolysis, the insoluble residue was removed by centrifugation and the hydrolysate dried in vacuo. The dry hydrolysate was dissolved in $1 \mathrm{ml}$ of a $0 \cdot 2 \mathrm{M}$-sodium citrate buffer, $\mathrm{pH} 2 \cdot 2$, containing norleucine as internal standard. Amino acids, in $250 \mu \mathrm{l}$ aliquots of the solution, were analysed according to Spackman et al. (1958), as modified by Piez \& Morris (1960), using a Beckman analyser.

Fatty acid analysis. The polymers were hydrolysed in methan$\mathrm{ol} / \mathrm{HCl} /$ water ( $82: 86: 9$ by vol.) as described by Mansson et al. (1978). Methyl esters of fatty acids were extracted in $n$-hexane and analysed by 
GLC before and after catalytic hydrogenation (Dias Filho et al., 1985). A stainless-steel column [6 $\mathrm{ft} \times \frac{1}{8}$ in $\left.(1.82 \mathrm{~m} \times 3 \mathrm{~mm})\right]$ with $10 \%$ diethyleneglycol succinate (DEGS) on Gas Chrom Q 100-120 mesh at $190^{\circ} \mathrm{C}$ was used.

Transmission electron microscopy. Hyphal and conidial forms treated with $0.5 \mathrm{M}-\mathrm{NaOH}(2,8$ and $18 \mathrm{~h})$ for pigment extraction, as described above, as well as untreated cells, were fixed, dehydrated in acetone, and embedded in Epon, as described previously by De Souza \& Meyer (1975). Ultra-thin sections of pigmented fungi were collected on gold grids and stained by the periodic acid/thiosemicarbazide/silver proteinate technique of Thiéry (1967). In this method, exposure to silver proteinate of the thiosemicarbazones which are formed can be examined by electron microscopy as silver deposits on the reactive sites. Control sections were treated similarly except for the lack of one of the three reagents. In some experiments the first step (periodic acid treatment) was omitted in order to reveal naturally occurring aldehyde groups.

Infrared spectra. These were obtained using a double-beam Perkin Elmer spectrometer (model 467) and $\mathrm{KBr}$ pellets (Stevenson \& Goh, 1972). Precautions were taken for elimination of moisture-interference according to Stevenson \& Goh (1974).

\section{Results}

Cultures grown in the chemically defined medium consisted of septate hyphae; the individual elongated cells often appeared swollen as in a pseudo-mycelium. Egg-shaped microconidia, easily detachable from the mycelium in shaken cultures with a short incubation time, occurred either as single cells or as strings of cells. After longer incubation periods, most conidia gave rise to hyphae. The formation of strings of conidia was stimulated by certain substances, e.g. propranolol (unpublished observation). The medium used to foster the appearance of sclerotic-like forms was rather simple, and the cell morphology did not depend on the $\mathrm{C}$ (glycerol) or $\mathrm{N}$ (ammonium nitrate) sources used. It is possible that addition of vitamins or lack of iron, which is a component of the CD medium, may have influenced cell morphology but this was not investigated further. The various cell types obtained in the synthetic medium are shown in Fig. 2.

\section{Chemical constitution of $F$. pedrosoi melanin}

Pigmented and non-pigmented cells were obtained as described in Methods. Both pigmented and nonpigmented mycelia were extracted by the same method for comparison of constituents. The black pigment of $F$. pedrosoi had properties similar to those of fungal melanins identified by Ellis \& Griffiths (1974). These pigments are insoluble in water, dilute acids and organic solvents (such as acetone, chloroform and ethanol), and soluble in alkali.

The high molecular mass of the pigmented complex was inferred from the fact that it did not penetrate
Table 1. Chemical constitution of purified melanin extracts from $F$. pedrosoi

\begin{tabular}{lcc}
\hline \hline & Content $\left.[\mathrm{mg} \text { (g wet mycelium) })^{-1}\right]^{*}$ \\
\cline { 2 - 3 } Constituent & Non-pigmented & Pigmented \\
\hline Ash & $0 \cdot 46$ & $5 \cdot 7$ \\
Carbon & $0 \cdot 6$ & $15 \cdot 4$ \\
Nitrogen & $0 \cdot 1$ & $1 \cdot 3$ \\
Protein & $0 \cdot 24$ & $4 \cdot 0$ \\
Total carbohydrate & $0 \cdot 4$ & $2 \cdot 7$ \\
Mannose & $0 \cdot 12$ & 0.5 \\
Galactose & $0 \cdot 18$ & $1 \cdot 0$ \\
Glucose & $0 \cdot 12$ & $0 \cdot 7$ \\
Rhamnose & ND & $0 \cdot 2$ \\
Hexosamine & ND & 0.04 \\
Phosphate & trace & trace \\
\hline \hline
\end{tabular}

ND, Not detected.

* Mean values from three independent purified extracts; variability was $2-3 \%$ of the mean.

Amicon membranes with an exclusion limit of $100 \mathrm{kDa}$.

The yield of extracted melanin in relation to the fungal wet mass was $2.7 \mathrm{~g}$ per $100 \mathrm{~g}$. The solid material in an extract obtained from a non-pigmented mycelium, following the same procedure, had a mass of $0.2 \mathrm{~g}$ per 100 g. Analyses of these acid-insoluble materials from mycelial extracts are shown in Table 1. The melanin fraction contained acidic groups with total acidity of 2.56 mequiv. $\mathrm{g}^{-1}$.

\section{Carbohydrate and amino acid contents}

The purified melanin contained rhamnose, mannose, galactose and glucose as shown by paper chromatography. The presence of these neutral sugars (in the ratio $1: 2: 4: 3 \cdot 5$, respectively) was confirmed by GLC. The lability of the galactose units to partial hydrolysis in dilute acid suggested the presence of galactofuranose units in the complex.

Glucosamine, detected at a concentration of $0.15 \%$ (w/w of pigment), was assayed colorimetrically and identified by paper chromatography.

The amino acid composition of the melanin from $F$. pedrosoi is shown in Table 2. Aspartic acid, glutamic acid, leucine, glycine and alanine were the major components.

Sialic acids were not detected using a colorimetric method.

\section{Determination of fatty acids}

Analysis of the contents of individual fatty acids showed that saturated fatty acids predominated in the lipidic 

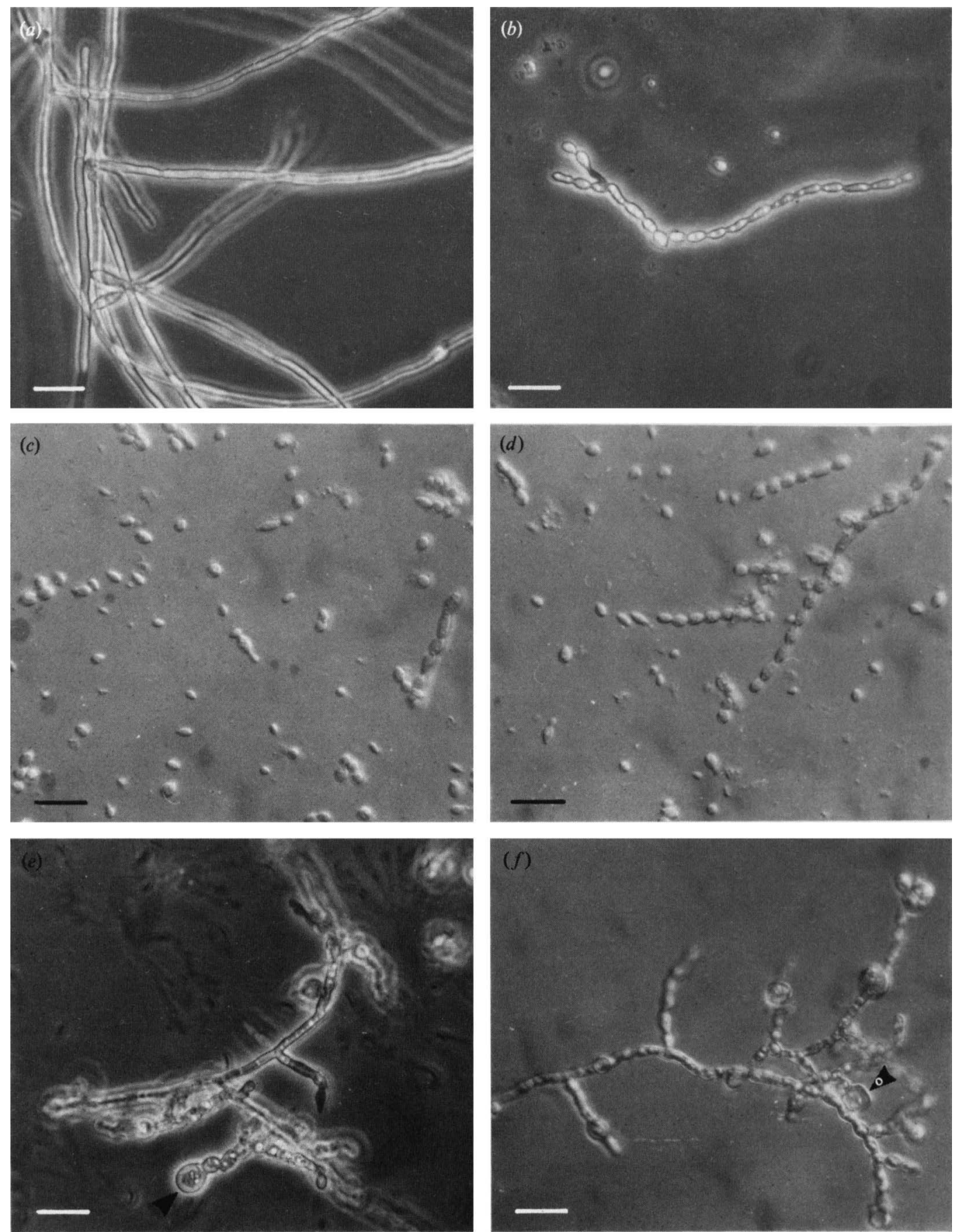

Fig. 2. F pedrosoi cell types in chemically defined media: $(a, b)$ hyphae; $(b)$ shows morphology resembling a pseudohypha; $(c, d)$ conidia; $(d)$ shows strings of cells; $(e, f)$ sclerotic-like cells (arrowheads). $(a, b, e)$ Phase contrast; $(c, d, f)$ interferential contrast. Bars, $20 \mu \mathrm{m}$.

part of the melanin complex. Palmitic, oleic, stearic and linoleic acids were found in the ratio $3 \cdot 5: 2: 1 \cdot 5: 0 \cdot 5$. The nature of the unsaturated fatty acids was also confirmed by examining the products of their catalytic reduction.

\section{Electron microscopy and ultrastructural cytochemistry}

The mycelial melanin was concentrated on large, strongly membrane-bound, electron-dense bodies localized intracellularly in hyphae and conidia (Fig. 3a). 

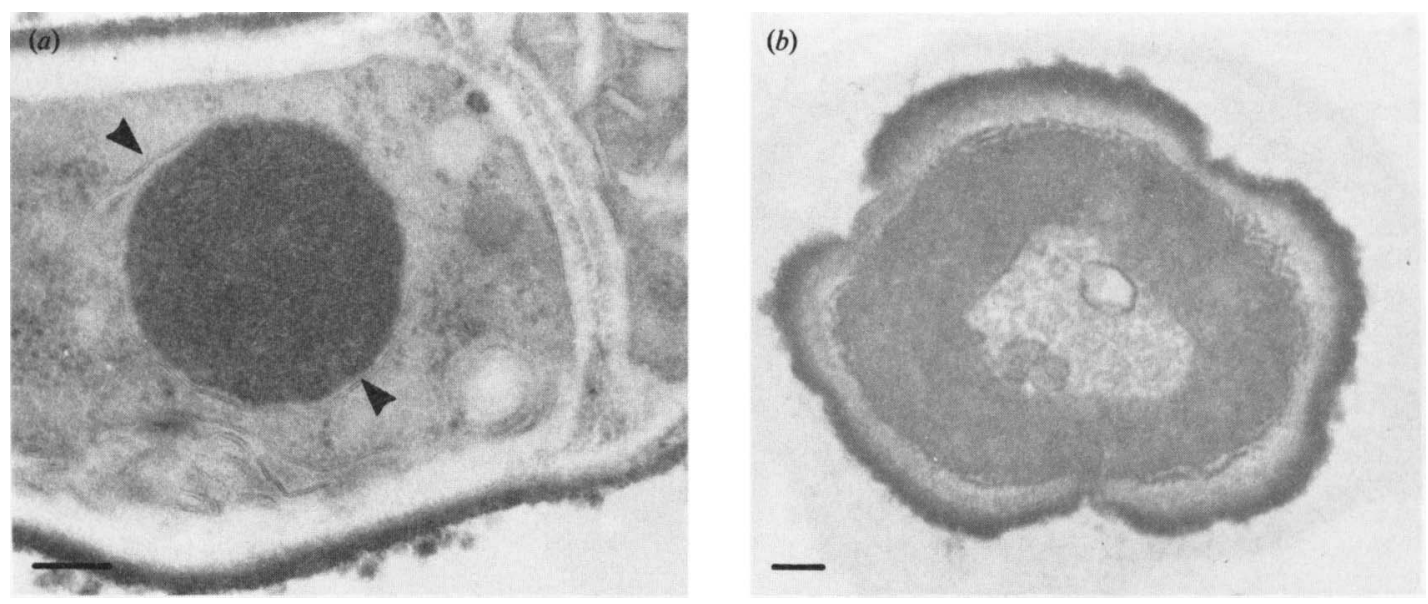

Fig. 3. Transmission electron microscopy of thin sections of $F$. pedrosoi. When the fungus is grown under conditions in which the pigment is synthesized, a membrane-bound electron-dense structure is seen in the cytoplasm (arrowheads, $a$ ). This structure is not seen when melanin was not synthesized $(b)$. Bars, $0 \cdot 2 \mu \mathrm{m}$.
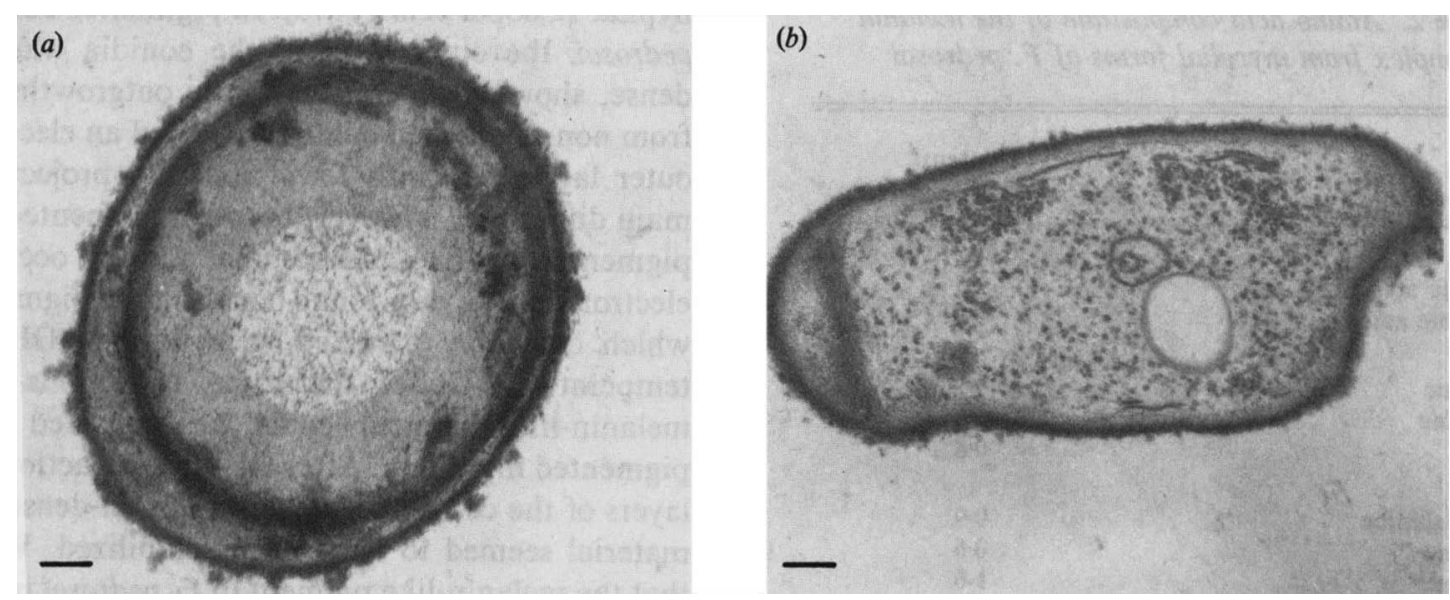

Fig. 4. Electron micrographs showing pigmented cells after alkali treatment for $8 \mathrm{~h}(a)$ and $18 \mathrm{~h}(b)$. Progressive extraction of melanin is evident. Bars, $0 \cdot 2 \mu \mathrm{m}$.

Fungal cells grown under conditions in which pigments are not synthesized did not form similar structures (Fig. 3 b). Alkali-treatment of pigmented cells for 8 and $18 \mathrm{~h}$ resulted in a progressive extraction of melanin (Fig. $4 a$ and $b$, respectively). By use of the periodic acid/thiosemicarbazide/silver proteinate technique (Thiéry, 1967), electron-dense deposits in granules located at the periphery of the cell were seen. They reacted as glycogenlike particles (Fig. $5 a$ ). However, when the periodic acid oxidation step was omitted in this technique, a positive reaction product, indicative of the presence of naturally occurring aldehyde groups, was observed on the electrondense cytoplasmic bodies (Fig. $5 b$ ).

\section{Infrared spectroscopy}

The infrared spectrum of the fungal melanin showed hydroxyl and carbonyl $\left(1715 \mathrm{~cm}^{-1}\right)$ groups and a band at $1615 \mathrm{~cm}^{-1}$ attributable to either a carboxylate anion or an aromatic structure. A large band at $2870 \mathrm{~cm}^{-1}$ and another at $2920 \mathrm{~cm}^{-1}$ consistent with an aliphatic structure, were also observed.

\section{Discussion}

Previous ultrastructural studies on dematiaceous fungi (Cole, 1986) indicated that the dark pigment was 

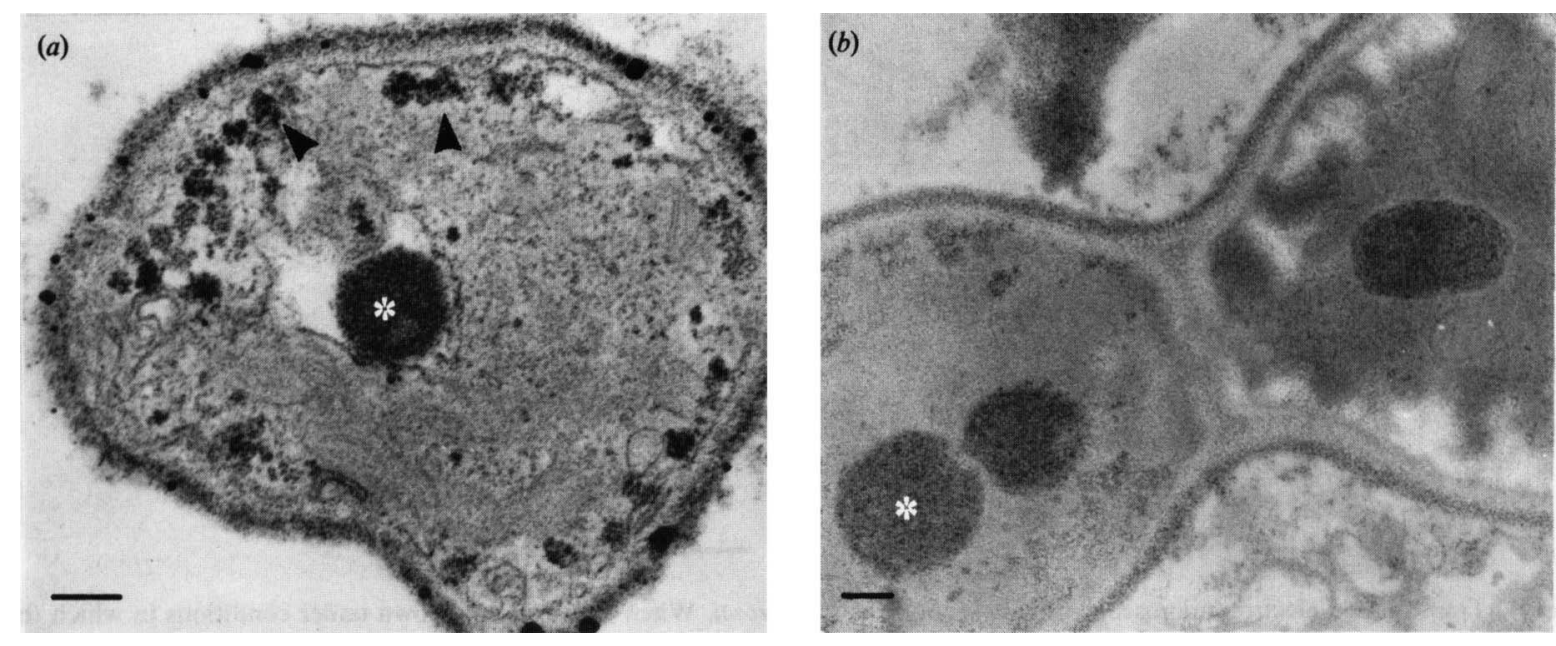

Fig. 5. Staining of thin sections of pigmented cells by the periodic acid/thiosemicarbazide/silver proteinate technique. Labelling of the dense cytoplasmic structure (asterisk) and glycogen particles (arrowheads) can be seen $(a)$. The dense granules remained reactive even when the sections were not treated with periodic acid (asterisk, $b$ ). Bars, $0 \cdot 2 \mu \mathrm{m}$.

Table 2. Amino acid composition of the melanin complex from mycelial forms of $F$. pedrosoi

\begin{tabular}{lc}
\hline \hline & $\begin{array}{c}\text { Content } \\
\text { Amino acid }\end{array}$ \\
(mg per 100 mg melanin)
\end{tabular}

ND, Not detected.

* Mean values from three independent hydrolysates; variability was $2-3 \%$ of the mean.

deposited on the outer layers of the cell wall and that melanin was packed in electron-dense grains 30 to $150 \mathrm{~nm}$ in diameter (Rast et al., 1981). Sclerotic cells of Phialophora verrucosa had a greater number of electrondense layers carrying the pigment than vegetative hyphae (Cooper et al., 1973). In pigmented cultures of $F$. pedrosoi, the outer layer of the conidia was electrondense, showing several verrucose outgrowths. Conidia from non-pigmented cultures also had an electron-dense outer layer, but with fewer external projections. The main difference, however, between pigmented and nonpigmented hyphae and conidia was the occurrence of electron-dense cytoplasmic bodies in the pigmented cells which could be extracted with $0.5 \mathrm{M}-\mathrm{NaOH}$ at room temperature. Under the same conditions the dark melanin-like pigment could be extracted from the pigmented mycelium. After alkaline extraction the outer layers of the cell wall were still electron-dense but some material seemed to have been solubilized. We suggest that the melanin-like pigment in F. pedrosoi is deposited partly on the cell wall, but mostly on cytoplasmic melanosomes. These structures coexist with glycogenlike particles which are stained by the periodate/thiosemicarbazide/silver proteinate method and located at the cell periphery. By omitting periodate treatment in Thiéry's method, naturally occurring aldehyde groups were detected on the same electron-dense cytoplasmic bodies, suggesting that they contain melanin. Carbonyl groups on the isolated pigment were also detected by infrared spectroscopy. Limited observations were made with sclerotic cells. In many cases these cells showed complete internal disintegration as observed for sclerotic cells of $P$. verrucosa (Nishimoto, 1970; Rosen et al., 1980). Interestingly, previous ultrastructural studies in Agaricus bisporus also suggested compartmentation of fungal melanins (Hegnauer et al., 1985). Thus, fungal melanin deposition seems to occur in subcellular organelles, as is the case in animal cells, in which melanins are produced and contained in melanosomes (Seiji, 1981). 
Elemental analysis of the dark pigment extracted from $F$. pedrosoi gave values for $\mathrm{C}$ and $\mathrm{N}$ of 5.7 and $4.8 \%$, respectively. These values are within the range reported for several fungal melanins examined (Coelho et al., 1985; Schnitzer et al., 1973).

The infrared spectra of $F$. pedrosoi melanin showed characteristic absorption bands corresponding to aromatic and aliphatic/glycosidic constituents: an important feature was the predominance of aliphatic/glycosidic structures over aromatic ones. Many fungal melanins also contain considerable amounts of aliphatic components (Stevenson \& Goh, 1972; Senesi et al., 1987). In turn, the aromatic constituents of melanin, which resemble soil humic acid (Filip et al., 1974), give rise to complex structures that bind to other pigment components (Haworth, 1971).

Rhamnose, mannose, glucose and galactose, were the glycosidic units detected in hydrolysates of $F$. pedrosoi pigment as assessed by paper and GLC. Galactose units are probably in the galactofuranosidic configuration. Glucosamine was present only in trace quantities. These carbohydrate units were also found in other fungal melanins (Schinitzer \& Chan, 1986). The total carbohydrate content $(10 \%)$ of the $F$. pedrosoi pigment is above the range $(1 \cdot 1-4 \cdot 4 \%)$ obtained for other fungal melanins (Linhares \& Martin, 1979; Coelho et al., 1988). Sialic acid, previously detected on the external layers of the $F$. pedrosoi cell wall (Souza et al., 1986), was not a constituent of the dark pigment. Galactofuranosyl units, present in $F$. pedrosoi, have also been found in galactomannans, which are immunogenic in rabbits, and have been isolated from the mycelium and spent media of $F$. (Hormodendrum) pedrosoi cultures (Suzuki \& Takeda, 1977).

Spectroscopic analysis and studies of model polymers suggest that the carbohydrate units are linked to the aromatic polymer through ester linkages. Other linkages may involve the amino groups of amino sugars, or amino acid units of complex glycoconjugates (Coelho et al., 1988).

Aspartic acid, glutamic acid, leucine, glycine and alanine were the predominant amino acids of the polypeptide in $F$. pedrosoi pigment. A similar distribution of the main amino acid was observed in a limited number of fungal melanins (Coelho et al., 1985). It has been postulated that during the melanin polymerization process, peptides are covalently linked to aromatic quinones by a nucleophilic reaction involving free $-\mathrm{NH}_{2}$ and -SH groups (Flaig et al., 1975; Haider et al., 1975).

Even-numbered, saturated and unsaturated fatty acids, ranging from $\mathrm{C}_{16}$ to $\mathrm{C}_{18}$, were components of the lipid moiety of $F$. pedrosoi melanin. A preferential incorporation of saturated fatty acids apparently took place in the pigment synthesis. Oleic and linoleic acids were the unsaturated fatty acids identified. Fatty acids in fungal melanins have also been studied by Saiz-Jimenez (1983) in Coprinus spp.: $\mathrm{C}_{12}$ to $\mathrm{C}_{24}$ species were found.

In conclusion, according to current concepts, melanins consist of micelles of a polymeric nature, the basic structure of which is an aromatic ring of the di- or trihydroxyphenol type combined with fatty acids, saccharides and amino compounds to form $\mathrm{N}$-containing polymers (Stevenson, 1986). Some of the common chromophoric groups, including nitroso, nitrile, azo and quinones, may be responsible for the dark colour of melanin (Stevenson, 1986).

In the present work we also compared pigmented with non-pigmented cells of $F$. pedrosoi. Using the same extraction procedure, the residue from the non-pigmented mycelium represented only $7.4 \%$ of the corresponding mass of the extracted melanin from pigmented cells. This indicates that the pigment complex is a typical biosynthetic product of the pigmented cells resulting from the assembly of non-pigmented precursors which do not accumulate in the bound, acid-insoluble form in the nonpigmented cells. The composition of the insoluble residue from the latter differs from that of the pigmented material obtained from dark cells, using the same extraction procedure.

Although the various components that make the dark pigment complex cannot be considered separately in terms of potential effects on fungal virulence, their individual action may help to understand some of the host-pathogen interactions. Melanin synthesis seems to be related to the pathogenicity of dark-pigmented fungi (Cooper, 1985).

The pigment in chromoblastomycotic fungi may serve as protection against intracellular destruction by macrophages (Reiss \& Nickerson, 1974). Lipids from $F$. pedrosoi mycelial forms, presumably including structures similar to those bound to the melanin complex, induced granulomatous reactions in mice (Silva \& Ekizlerian, 1985). The peptide portion of the complex might have a role in the chelation of cations, competing with other metal-binding serum proteins of the host. The carbohydrate part, on the other hand, might affect cell recognition and cell-cell interactions important for the survival of the fungal infective form. These aspects are currently under investigation.

This investigation was supported by CNPq, CEPG-UFRJ, FINEP and FAPERJ. We thank Valter Trajano de Lima and Luiz Rodrigues da Silva for technical assistance and Mrs Alba Valéria Peres for typing the manuscript.

\section{References}

AMEs, B. N. (1966). Assay of inorganic phosphate, total phosphate and phosphatases. Methods in Enzymology 8, 115-118. 
Belcher, R., Nuttene, A. J. \& Sambrook, C. M. (1954). The determination of glucosamine. Analyst 97, 201-208.

Bremner, J. M. (1965). Total nitrogen. In Methods of Soil Analysis, pp. 1149-1178. Edited by C. A. Black. Madison, Wisconsin: American Society of Agronomy.

Bull, A. T. (1970). Inhibition of polysaccharides by melanin: enzyme inhibition in relation to mycolysis. Archives of Biochemistry and Biophysics 137, 345-356.

ButTER Field, W. \& JoNG, S. G. (1976). Effect of carbon source on conidiogenesis in Fonsecaea dermatitidis, agent of chromomycosis Mycopathologia 58, 59-62.

Coelho, R. R. R., Linhares, L. F. \& Martin, J. P. (1985). Amino acids distribution in some fungal melanins and of soil humic acids from Brazil. Plant and Soil 87, 337-346.

Coelho, R. R. R., Linhares, L. F. \& Martin, J. P. (1988). Sugars in hydrolysates of fungal melanins and soil humic acids. Plant and Soil 106, 127-133.

COLE, G. T. (1986). Models of cell differentiation in conidial fungi. Microbiological Reviews 50, 95-132.

CoOper, B. H. (1985). Phialophora verrucosa and other chromoblastomycotic fungi. In Fungal Dimorphism, with Emphasis on Fungi Pathogenic for Humans, pp. 263-280. Edited by P. J. Szanislo. New York: Plenum Press.

Cooper, B. H., Grove, S., Mims, S. \& Szaniszlo, P. J. (1973). Septal ultrastructure in Phialophora pedrosoi. Phialophora verrucosa and Cladosporum carrioni. Sabouraudia 11, 127-130.

De SouzA, W. \& MeYer, H. (1975). An electron microscopic and cytochemical study of the cell coat of Trypanosoma cruzi in tissue cultures. Zeitschrift für Parasitenkunde 46, 179-187.

Dias Filho, B. P., Alviano, C. S., De Souza, W. \& Angluster, J. (1985). Fatty acids and sterols of Tritrichomonas foetus. Comparative Biochemistry and Physiology 81B, 515-518.

Dubois, M., Gilles, K. A., Hamilton, J. K., Rebers, P. A. \& Smith, F. (1956). Colorimetric method for determination of sugars and related substances. Analytical Chemistry 28, 350-356.

Ellis, D. H. \& Griffiths, D. A. (1974). The location and analysis of melanins in the cell walls of some soil fungi. American Journal of Microbiology 20, 1379-1386.

Ellis, M. B. (1976). More Dematiaceous Hyphomycetes. Kew: Commonwealth Mycological Institute.

Filip, Z., Haider, K., Bentelspacher, H. \& Martin, J. P. (1974). Comparisons of I.R.-spectra from melanins of microscopic soil fungi, humic acids and model phenol polymers. Geoderma 11, 37-52.

Flaig, W., Bentelspacher, H. \& Rietz, E. (1975). Chemical composition and physical properties of humic substances. In Soil Components, pp. 1-211. Edited by J. E. Greseking. New York Springer-Verlag.

GaLAmBOS, J. T. (1967). The reaction of carbazole with carbohydrates. II. Effect of borate and sulfonate on the ultraviolet absorption of sugars. Analytical Biochemistry 19, 133-143.

Geis, P. A., Wheeler, M. H. \& Szaniszlo, P. J. (1984). Pentaketide metabolites of melanin synthesis in the dematiaceous fungus Wangiella dermatitidis. Archives of Microbiology 137, 324-328.

Haider, K., Martin, J. P. \& Filip, Z. (1975). Humus biochemistry. In Soil Biochemistry, vol. 4, pp. 195-244. Edited by E. A. Paul \& A. D. McLaren. New York: Marcel Dekker.

HAWORTH, R. D. (1971). The chemical nature of humic acid. Soil Science 11, 71-79.

Hegnauer, H., NyHLÉN, L. E. \& RAST, D. M. (1985). Ultrastructure of native and synthetic Agaricus bisporus melanins - implications as to the compartmentation of melanogenesis in fungi. Experimental Mycology 9, 221-229.

Linhares, L. F. \& Martin, J. P. (1979). Carbohydrates content of fungal humic acid-type polymers (melanin) of Eurotium echinulatum, Aspergillus glaucus spp. and other fungi. Soil Science Society of America Journal 42, 313-318.

Mansson, J. E., VANier, M. T. \& Suennerholm, L. (1978). Changes in the fatty acid and sphingosine composition of the major gangliosides of human brain with age. Journal of Neurochemistry 30, 273-275.

MORRISON, I. M. (1988). Hydrolysis of plant cell walls with trifluoroacetic acid. Phytochemistry 27, 1097-1100.

Nishimoto, K. (1970). Electron microscopic findings of lymph nodes affected by chromomycosis. Japanese Journal of Dermatology, Series A 80, 181-195.
Oliveira, L. G., Resende, M. A., lopes, C. F. \& Cisalpino, E. D. (1973). Isolamento e identifição dos agentes da cromomicose em Belo Horizonte. Revista da Sociedade Brasileira de Medicina Tropical 7, 7-10.

PIEZ, K. A. \& Morris, L. (1960). A modified procedure for automatic analysis of amino acids. Analytical Biochemistry 1, 187-201.

Rast, D. M., Stüssi, H., Hegnauer, H. \& Nyhlem, L. E. (1981). Melanins. In The Fungal Spore: Morphogenetic Controls, pp. $507-$ 531. Edited by G. Turian \& H. R. Hohl. New York: Academic Press.

Reiss, E. \&. Nickerson, W. J. (1974). Control of dimorphism in Phialophora verrucosa. Sabouraudia 12, 202-213.

Rosen, T., Gyorkey, F., Joseph, L. M. \& Batres, E. (1980) Ultrastructural features of chromoblastomycosis. International Journal of Dermatology 19, 461-468.

SAIZ-JimenEZ, C. (1983). The chemical nature of the melanins from Coprinus spp. Soil Science 136, 65-74.

Sawardeker, J. S., Slonecker, J. H. \& Jeanes, A. (1965) Quantitative determination of monosaccharides as their alditol acetates by gas liquid chromatography. Analytical Chemistry 37, 1602-1604.

SChINITZER, M. \& CHAN, Y. K. (1986). Structural characteristics of a fungal melanin and a soil humic acid. Soil Science Society of America Journal 50, 67-71.

Schinitzer, M., Ortez da Serra, M. I. \& Ivarson, K. (1973). The chemistry of fungal humic acid. Soil Science Society of America Proceedings 37, 229-236.

Seivi, M. (1981). Melanosomes. In Pigment Cell. Phenotypic Expression in Pigment Cells, pp. 3-13. Edited by M. Seiji. Tokyo: University of Tokyo Press.

Senesi, N., Miano, T. M. \& Martin, P. (1987). Elemental, functional infrared and free radical characterization of humic acid-type fungal polymers melanins. Biology and Fertility of Soils 5, 120-125.

Silva, C. L. \& Ekizlerian, S. M. (1985). Granulomatous reaction induced by lipids extracted from Fonsecaea pedrosoi, Fonsecaea compactum, Cladosporium carrionii and Phialophora verrucosum. Journal of General Microbiology 131, 187-194.

Souza, E. T., Silva-Filho, F. C., De Souza, W., Alviano, C. S., Angluster, J. \& Travassos, L. R. (1986). Identification of sialic acids on the surface of hyphae and conidia of the human pathogen Fonsecaea pedrosoi. Journal of Medical and Veterinary Mycology 24, 145-153.

Spackman, D. H., Stein, W. H. \& Moores, S. (1958). Automatic recording apparatus for use in the chromatography of amino acids. Analytical Chemistry 30, 1190-1206.

Stevenson, F. J. (1986). The carbon cycle. In Cycles of Soil, Carbon, Nitrogen, Phosphorus, Sulfur, Micronutrients, pp. 1-44. Edited by F. J. Stevenson. New York: Wiley Interscience.

Stevenson, F. J. \& GoH, K. M. (1972). Infrared spectra of humic and fulvic acids and their methylated derivatives: evidence for nonspecificity of analytical methods for oxygen containing functional groups. Soil Science 113, 334-345.

Stevenson, F. J. \& GoH, K. M. (1974). Infrared spectra of humic acids: elimination of interference due to hygroscopic moisture and structural changes acompanying heating with $\mathrm{KBr}$. Soil Science $\mathbf{2}$, 34-41.

Sussman, A. S. (1968). Longevity and survivability of fungi. In The Fungi, vol. 3, pp. 447-486. Edited by G. C. Ainsworth \& A. S. Sussman. New York: Academic Press.

Suzuki, S. \& TAKEDA, N. (1977). Immunochemical studies on the galactomannans isolated from mycelia and culture broths of three Hormodendrum strains. Infection and Immunity 17, 483-490.

TAylor, B. E., Wheeler, M. H. \& Szaniszlo, P. J. (1987). Evidence for pentaketide melanin biosynthesis in dematiaceous human pathogenic fungi. Mycologia 79, 320-322.

THIÉRY, J. P. (1967). Mise en évidence des polysaccharides sur coupes fines en microscopie électronique. Journal de Microscopie 6, 9871018.

Travassos, L. R. (1985). Sporothrix schenckii. In Fungal Dimorphism, with Emphasis on Fungi Pathogenic for Humans, pp. 121-163. Edited by P. J. Szaniszlo. New York: Plenum Press.

WhITE, L. P. (1958). Melanin: a naturally occurring cation exchange material. Nature, London 182, 1427-1428. 